\title{
Editorial
}

\section{The first 25 years of Acta Dermatovenerologica Alpina, Pannonica et Adriatica}

\author{
Jovan Miljković, Editor in Chief
}

The publication of the first issue of Acta Dermatovenerologica Alpina, Pannonica et Adriatica (Acta Dermatovenerol APA) 25 years ago was the result of the vision of a single exceptional man: Aleksej Kansky, one of the leading figures in the history of dermatology in Slovenia and central Europe. The primary intention was for the journal to function as forum for research and discussion articles, sharing the ideas and experience of professionals in the region. The journal was also to serve as a platform to assist young dermatologists in the region in publishing their first peerreviewed manuscripts.

The first issue appeared in spring 1992, with the support of prominent dermatologists including H. Peter Soyer, Stefan Hödl, Helmut Kerl (Graz), Carmelo Scarpa, Giusto Trevisan (Trieste), Janez Fettich, Marko Potočnik (Ljubljana), Marija Berčič (Maribor), Günter Burg (Zurich), and Michael Lomuto (San Giovanni Rotondo). In the very first volume of the journal, its contributors already hailed from a variety of European countries (Germany, Austria, Italy, and Bosnia and Herzegovina), signaling its international character.

For the first 15 years, Aleksej Kansky worked hard to establish and maintain quality of the journal. In 2009, Aleksej Kansky stepped down as editor-in-chief and became editor emeritus, and Jovan Miljković took over as acting editor-in-chief assisted by

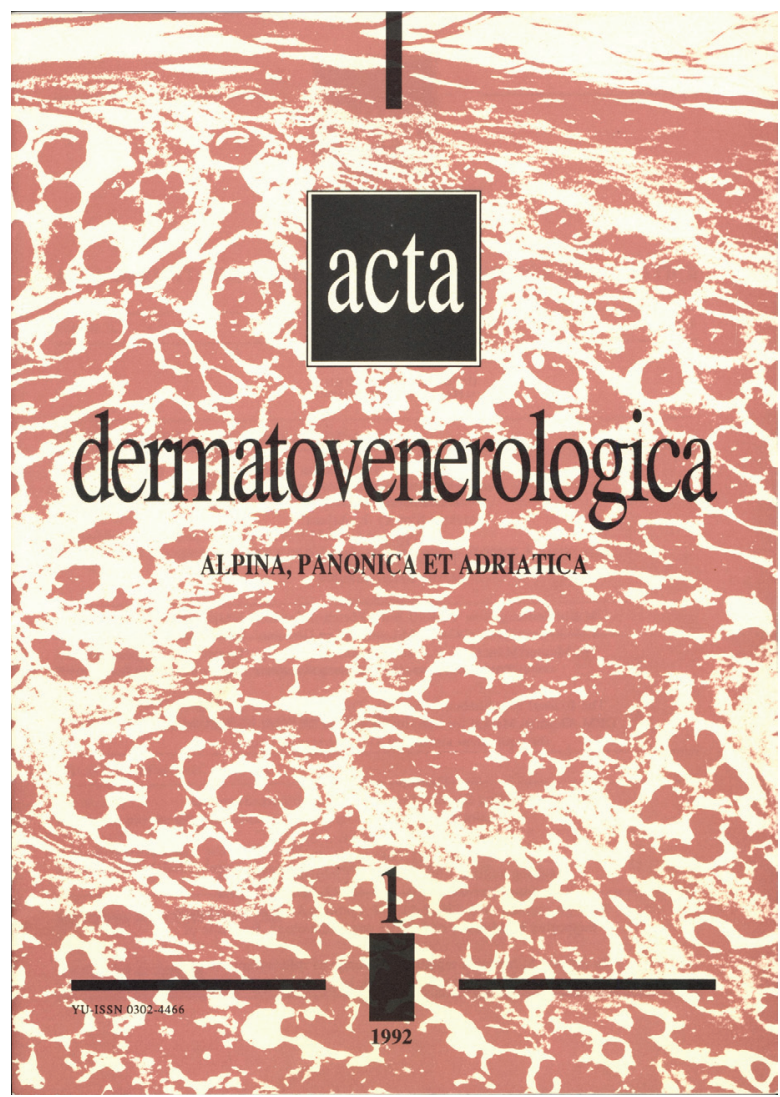

Mario Poljak as associate editor.

Now we celebrate the 25th anniversary of the journal and can look back over these 25 years of hard work and achievements.

The Slovenian Dermatology Society was founded in 1999, and it became the official publisher of the journal. Since 2000, Acta Dermatovenerol APA has been an open-access journal with the entire content of the journal freely available at the journal's website: http://www.acta-apa.org/.

In 2005, the journal achieved full indexing status in Index Medicus/MEDLINE, EMBASE/Excerpta Medica, and Biomedicina Slovenica. The entire content of the journal has been included in Pubmed, the most important database for medical journals.

Although Acta Dermatovenerol APA is a "small journal from a small country," it has significantly improved its quality and international profile over the last 25 years. When celebrating the 25th anniversary of Acta Dermatovenerol APA, we return once again to the vision of its founding editor, Aleksej Kanksy, and to the people that translated his vision into reality. The best recognition of their efforts is certainly the news that Thomson Reuters accepted Acta Dermatovenerol APA this year for coverage in the new Thomson Reuters Web of Science Core Collection index called the Emerging Sources Citation Index (ESCI).

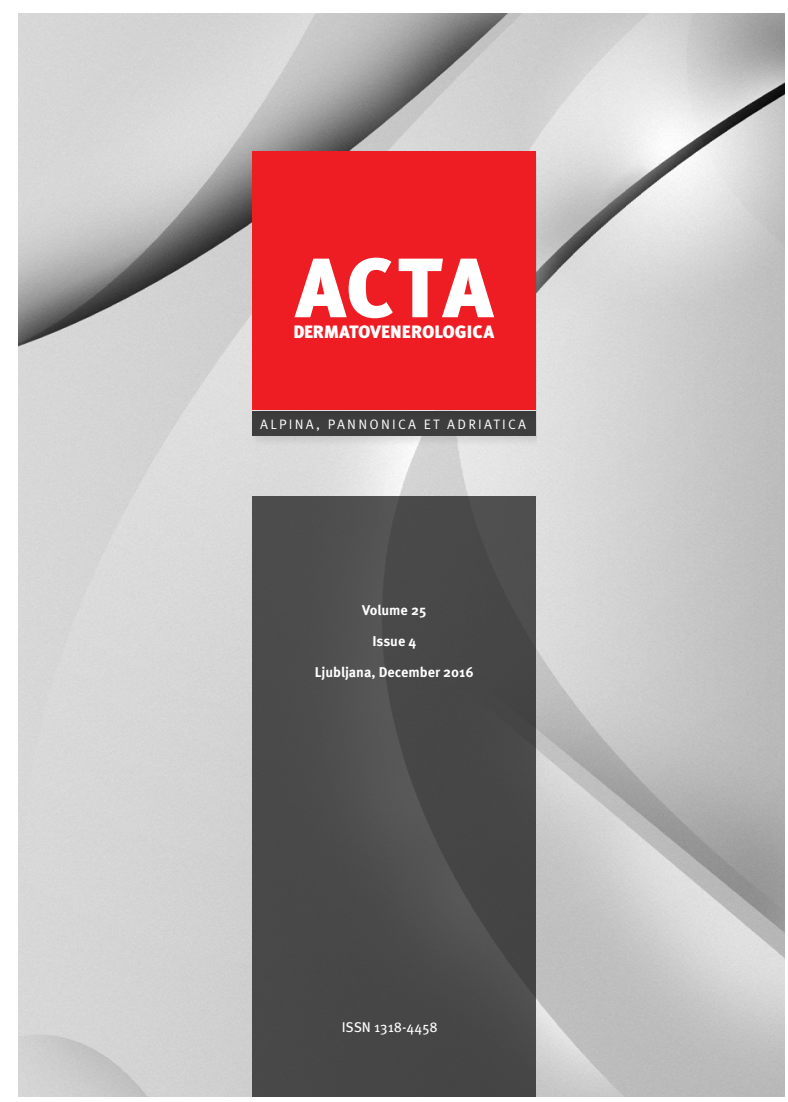

